\title{
Development of an improved cracking method to reduce the variability in testing the healing efficiency of self-healing mortar containing encapsulated polymers
}

\author{
Tim Van Mullem ${ }^{1}$, Kim Van Tittelboom ${ }^{1}$,Elke Gruyaert $^{2}$, Robby Caspeele $^{1}$ and Nele De Belie ${ }^{1 *}$ \\ ${ }^{1}$ Magnel Laboratory for Concrete Research, Department of Structural Engineering, Ghent University, Tech Lane Ghent Science Park, \\ Campus A, Technologiepark Zwijnaarde 904, B-9052 Gent, Belgium \\ 2 Department of Civil Engineering, Technology Cluster Construction, Structural Mechanics and Building Materials, KU Leuven, \\ Gebroeders De Smetstraat 1, B-9000 Gent, Belgium
}

\begin{abstract}
Concrete cracking can result in a significant reduction of the durability and the service life due to the ingress of aggressive agents Self-healing concrete is able to heal cracks without external intervention, thereby mitigating the need for manual repair. In the assessment of the healing efficiency of self-healing concrete the to-be-healed crack width is an important parameter and different researchers have emphasised that the variability of the crack width significantly hampers an accurate assessment of the healing efficiency. With two new crack control techniques the variability of the crack width was reduced in order to decrease the variability on the calculated healing efficiency. This paper reports on the application of these techniques for the assessment of self-healing mortar containing encapsulated polyurethane. The healing potential was investigated by looking at the degree of sealing using a water flow test setup. It was observed that by using a crack control technique the variability on the crack width can indeed be reduced. Nonetheless, this does not translate in an equivalent reduction on the variability of the healing efficiency. This indicates that other factors contribute to the variability of the healing efficiency.
\end{abstract}

\section{Introduction}

Reinforced concrete is a commonly used construction material. Due to the low tensile strength, concrete can easily crack and these formed cracks provide a transport path for harmful substances to migrate into the concrete matrix and result in corrosion of the reinforcement. Manual repair of cracks is costly and often not practical. Therefore, self-healing concrete has been developed which is able to seal its own cracks, resulting in an increased durability and service life.

In order to test the sealing capacity of self-healing concrete a crack first needs to be induced, after which the actual testing can be performed. These tests are very sensitive to the variance in crack width [1-3]. In order to have a low variance in crack width standardised cracks are sometimes used, such as: non-through going cuts [4], cast-in metal plates to be pulled out after the initial setting of the concrete creating a non-through going cut [5], cracking the specimens in two halves and reattaching them [6],... These cracks however do not have a geometry which is commonly found in reality. For that reason it is often decided to induce the crack via a crack-width-controlled 3-point bending test, which allows to monitor the crack width during loading. After the loading is removed the crack width decreases to a residual crack width. This is the result of the elastic recovery of the reinforcement and the matrix. It has been noted that there can be quite some variance on this residual crack width, even if the cracking procedure is identical [2].

This paper reports on two different crack width control techniques to reduce the variance in crack width when a 3-point bending test is applied, in an attempt to reduce the variability on the sealing results. To test the sealing efficiency the water flow test $[2,3,7,8]$, which has been developed in the FP7 project HEALCON, has been used. Encapsulated polyurethane was chosen as a self-healing agent. The use of encapsulated polyurethane generally ensures a good and stable healing of cracks [9-11]. Thus this allows to limit the variance as a result of the healing mechanism as much as possible.

\section{Materials}

\subsection{Tubular capsules with healing agent}

As healing agent a commercially available singlecomponent polyurethane named Flex SLV was used. This agent has a super low viscosity and it polymerises when it comes in contact with moisture in the air [12]. In order to prevent the polymerisation up until the moment of crack creation the polyurethane was encapsulated in 
tubular glass capsules. The capsules were made from borosilicate glass and had an external diameter of $3.35 \mathrm{~mm}$, an internal diameter of $3 \mathrm{~mm}$ and a length of $50 \mathrm{~mm}$, similar as in [9-13]. One side of the capsules was first sealed with a double layer of polymethylmethacrylate. The polyurethane was then injected in the capsules using a syringe. Finally, the other end of the capsules was also sealed with polymethylmethacrylate and special care was taken to limit the entrapped air in the capsules as much as possible. Feiteira et al. [9] showed that this way of encapsulating polyurethane is able to keep the polyurethane stable for several months.

\subsection{Mortar composition}

For all mortar specimens which were cast, either reference specimens without a capsule or self-healing specimens containing one capsule, the mortar composition was the same. A cement type CEM I $42.5 \mathrm{~N}$ was used. The water to cement ratio was 0.5 and the sand to cement ratio was 3 . A standard sand $(0 / 2)$ was used. The mixing procedure was executed as described in EN 196-1. All specimens had dimensions of $40 \mathrm{~mm}$ by $40 \mathrm{~mm}$ by $160 \mathrm{~mm}$. Before and after demoulding the specimens were sealed and stored at $20^{\circ} \mathrm{C}$.

\section{Methods}

In an attempt to reduce the variability on the crack width two different crack width control techniques were investigated. For both methods the intended crack width was to be at maximum $300 \mu \mathrm{m}$.

\subsection{Spacer technique: crack width control technique using spacers}

The first crack width control technique which was investigated used spacers to restrict the elastic crack closure after unloading and to stop it as close to the intended crack width as possible. This technique is hereafter called the "Spacer technique".

The mortar prisms were provided with a cast-in notch with a trapezoidal shape, as can be seen in Fig. 1. The base part of the notch had a square shape with a height of $2.1 \mathrm{~mm}$ and a width of $5 \mathrm{~mm}$. The upper triangular part had a height of $2.8 \mathrm{~mm}$ and a base of $5 \mathrm{~mm}$. The specimens had two reinforcement wires with a diameter of $2 \mathrm{~mm}$ positioned at $10 \mathrm{~mm}$ above the bottom side of the specimens. Additionally, the specimens had a cast-in hole over their entire length with a diameter of $5 \mathrm{~mm}$ positioned at mid-height. This cast-in hole is required to test the water permeability using the water flow setup, see section 3.4. In each mould for self-healing specimens one capsule was placed in between the reinforcement wires, so that the distance between the top of the notch and the capsule would be approximately equal to the distance between the cast-in hole and the capsule.

At an age of 7 days the specimens were cracked in a crack-width-controlled 3-point bending test setup with a span of $10 \mathrm{~cm}$. The crack width during loading was measured with an LVDT positioned at the bottom side of the specimens. The specimens were cracked at a speed of $0.5 \mu \mathrm{m} / \mathrm{s}$ until the LVDT gave a reading of $560 \mu \mathrm{m}$. Immediately after unloading two prismatic spacers were inserted in the base square part of the notch of the specimens, thus stopping the elastic closing of the crack at the desired crack width. After the spacers were inserted in the notches the specimens were placed with their crack face upwards.

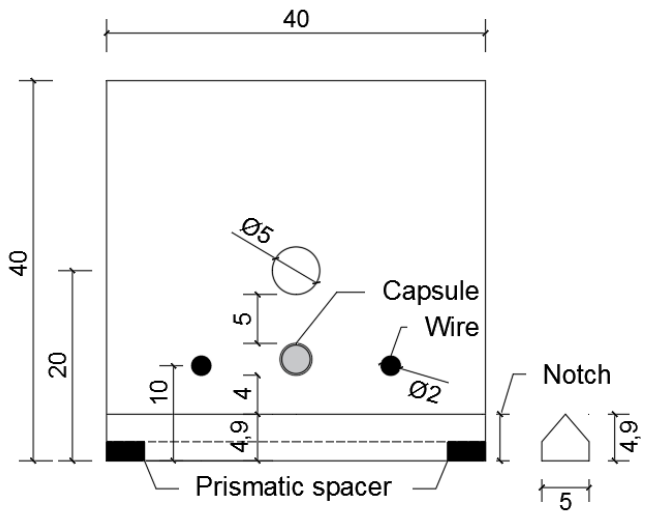

Fig. 1. Cross-section at mid-span of a specimen prepared according to the Spacer technique (dimensions in $\mathrm{mm}$ ).

\subsection{CFRP technique: crack width control technique using CFRP and screw jacks}

The second crack width control technique, termed the CFRP technique, used a different approach. The mortar prisms were not provided with any reinforcement wires. Instead a Carbon Fibre Reinforced Polymer (CFRP) strip with dimensions of $40 \mathrm{~mm}$ by $160 \mathrm{~mm}$ was glued on the top side of the mortar specimens a day before cracking. The CFRP which was used consisted of unidirectional carbon fibres embedded in epoxy. Due to its high tensile strength and high modulus of elasticity it is commercially used as external reinforcement. The castin hole required to perform the water flow test was positioned at a height of $15 \mathrm{~mm}$ from the bottom side, see Fig. 2. For the self-healing specimens the capsule was placed at a height of $5 \mathrm{~mm}$ above the bottom side of the specimen so that the distance between the cast-in hole and the capsule, and the distance between the capsule and the bottom side of the specimen would be approximately equal. The distances are comparable to the layout of the Spacer technique, where the top of the notch should be used as a reference instead of the bottom side of the specimen, as the crack will propagate from the top of the notch. At an age of 7 days the specimens were cracked until failure in a 3-point bending test setup with a span of $10 \mathrm{~cm}$. Both halves of the mortar specimen stayed together due to the CFRP. However, the crack between the two halves was too large. As a result of the stiffness of the CFRP the two halves could only move with one degree of freedom relative to one another: the crack could be opened or closed but the two halves could not be rotated relative to each other. Immediately after cracking the specimens were placed with their crack face upwards and the crack width was restrained using screw jacks to a nominal value of 
$400 \mu \mathrm{m}$. The crack width was then further restrained under the optical microscope using an iterative procedure of measuring and restraining until the desired crack width was obtained. Fig. 3 shows a typical specimen which has been restrained with the CFRP technique.

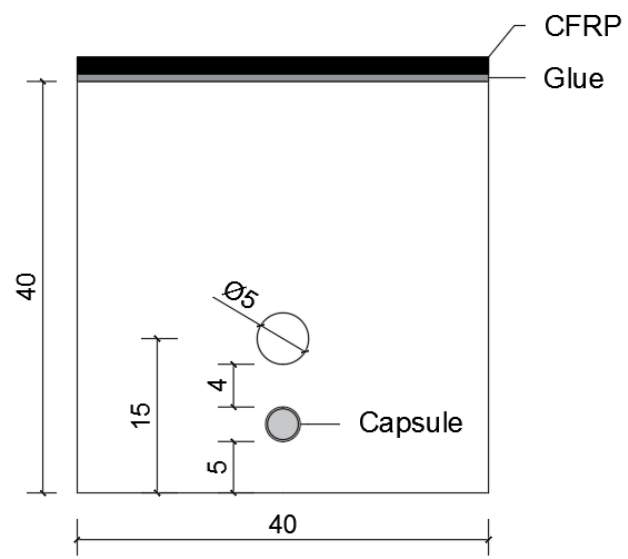

Fig. 2. Cross-section at mid-span of a specimen prepared according to the CFRP technique (dimensions in $\mathrm{mm}$ ).

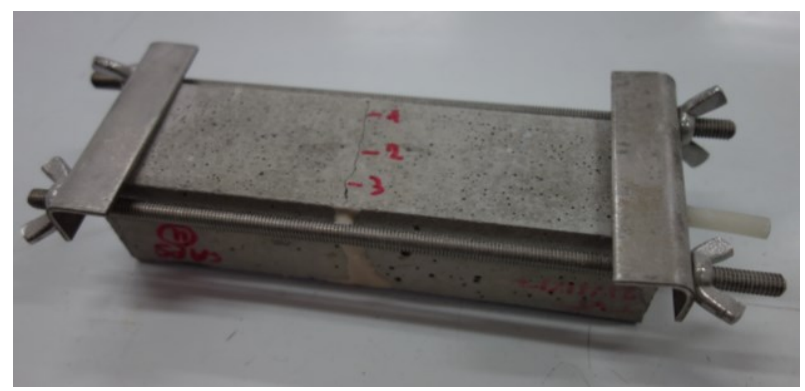

Fig. 3. Typical sample for which the crack width is controlled using the CFRP technique.

\subsection{Optical microscopy}

The crack width of each specimen was accurately determined using an optical crack microscope (Leica S8APO mounted with a DFC295 camera). Along the length of the crack 3 locations were chosen at random. For each location 4 to 5 measurements of the crack width were performed. The reported crack width is the mean of all these measurements.

\subsection{Water flow test}

The water flow test was first developed by Tziviloglou et al. [7] and was studied in detail by means of a Round Robin Test campaign after which some recommendations for further improvements were proposed [3]. One side of the specimen was connected to a water reservoir at a height of $500 \mathrm{~mm}$ with respect to the cast-in hole, see Fig. 4, while the other side of the specimen was completely sealed. The sides of the specimens were also sealed so that water could only leak out of the bottom of the crack. The amount of leaked water was recorded over time for a minimum of 5 minutes. The sealing efficiency of the self-healing specimens, containing a capsule with polyurethane, with respect to the reference specimens, without a capsule, can be calculated from Equation 1:

$$
S E=\left(W F_{R E F}-W F_{C A P S}\right) / W F_{R E F}
$$

with: - $S E$ the sealing efficiency;

$-W F_{R E F}$ the mean water flow $(\mathrm{g} / \mathrm{min})$ of the reference specimens;

$-W F_{C A P S}$ the mean water flow $(\mathrm{g} / \mathrm{min})$ of the selfhealing specimens containing a capsule.

The water flow test was performed on dry specimens and the time between water flow testing and cracking was well beyond the curing time of the polyurethane. Normally this test is performed on specimens which have been saturated for 2 days [2, 3, 7], but upon continuous contact with water unpolymerised polyurethane, which could have remained inside the capsules, could begin to foam and result in additional filling of the crack. Since all the specimens within one crack width control technique were cast, cracked and tested at the same days the water content of the specimens can be assumed as equal and can therefore not influence the results.

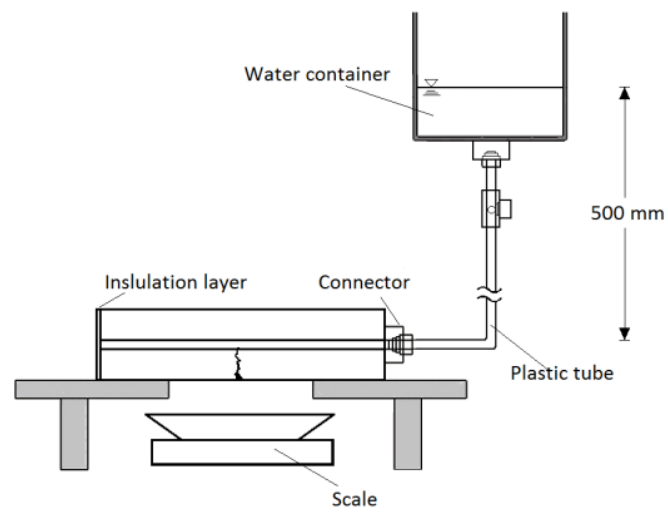

Fig. 4. Schematic drawing of water flow setup [2].

\section{Results and discussion}

\subsection{Crack width and water flow of specimens controlled with the Spacer technique}

For 5 reference specimens without capsules (REF) and for 6 self-healing specimens with a capsule (CAPS) the crack width was controlled using the Spacer technique. Table 1 shows the crack width of these specimens. For one specimen it was not possible to measure the crack width as the crack face was completely covered by the healing agent. The average of the 10 specimens of which the crack width could be measured is equal to $323 \mu \mathrm{m}$ with a coefficient of variance (COV) of $11.8 \%$. It seems that the crack width of the CAPS specimens is somewhat lower than the crack width of the REF specimens, although the entire procedure was identical for the two series.

Not all specimens have two spacers (one at each side of the notch). For 3 out of 11 specimens it was only possible to insert one spacer, since on the other side the prismatic part of the notch had been damaged during 
demoulding. For 1 specimen it was even impossible to insert a spacer in the notch because one part of the notch was also damaged and the crack had closed too much after unloading to insert the spacer on the other side. The fact that not all specimens contained two spacers does not seem to have influenced the crack width significantly. It is therefore debatable if the spacers provided an added value in reducing the variability of the crack width. Furthermore, the spacers were made from a combination of metallic precision plates and ASA (Acrylonitrile-Styreen-Acrylester) and it is possible that this ASA is too deformable to completely prevent the elastic closing of the crack. If this is the case the deformability of the spacers will also have influenced the variability of the crack width.

Table 1 also gives the results of the water flow test. The positive effect of the capsules is evident: 3 out of 6 CAPS specimens show complete sealing. There is only 1 specimen for which the water flow is comparable to the REF specimens, the remaining 2 specimens have a water flow which is significantly lower than the one from the REF specimens. Using Equation 1 a sealing efficiency of $80.2 \%$ can be calculated.

Table 1. Overview of the data of the specimens cracked according to the Spacer technique.

\begin{tabular}{lcccc}
\hline & $\begin{array}{c}\text { Mean } \\
\text { crack } \\
\text { width } \\
{[\boldsymbol{\mu} \text { m] }}\end{array}$ & $\begin{array}{c}\text { Standard } \\
\text { deviation } \\
\text { on crack } \\
\text { width } \\
{[\boldsymbol{\mu m}]}\end{array}$ & $\begin{array}{c}\text { Number } \\
\text { of } \\
\text { spacers }\end{array}$ & $\begin{array}{c}\text { Water } \\
\text { flow } \\
\text { [g/min] }\end{array}$ \\
\hline REF 1 & 309 & 17 & 1 & 61 \\
REF 2 & 322 & 12 & 2 & 72 \\
REF 3 & 379 & 9 & 1 & 117 \\
REF 4 & 350 & 6 & 2 & 97 \\
REF 5 & 373 & 4 & 2 & 112 \\
\hline CAPS 1 & 287 & 8 & 1 & 29 \\
CAPS 2 & 289 & 5 & 2 & 0 \\
CAPS 3 & $/$ & $/$ & 2 & 0 \\
CAPS 4 & 297 & 10 & 0 & 59 \\
CAPS 5 & 272 & 12 & 2 & 0 \\
CAPS 6 & 348 & 12 & 2 & 25 \\
\hline
\end{tabular}

\subsection{Crack width and water flow of specimens controlled with the CFRP technique}

Table 2 gives the crack width for the six reference specimens without capsules (REF) and the six self-healing specimens with a capsule (CAPS) for which the crack width was controlled using the CFRP technique. The average crack width of the 12 specimens is equal to $287 \mu \mathrm{m}$ with a COV of $2.8 \%$. The crack widths of the REF and the CAPS series are comparable: the general variance is quite low. All crack widths are also close to the intended crack width which was at maximum $300 \mu \mathrm{m}$.
The result of the water flow test is also given in Table 2. There is only 1 CAPS specimen which is completely healed. However, for the other CAPS specimens the water flow is significantly lower than the water flow of the REF specimens. Using Equation 2 a sealing efficiency of $65 \%$ can be calculated.

Table 2. Overview of the data of the specimens cracked according to the CFRP technique.

\begin{tabular}{lccc}
\hline & $\begin{array}{c}\text { Mean crack } \\
\text { width } \\
{[\boldsymbol{\mu} \mathbf{m}]}\end{array}$ & $\begin{array}{c}\text { Standard } \\
\text { deviation on } \\
\text { crack width } \\
{[\boldsymbol{\mu m}]}\end{array}$ & $\begin{array}{c}\text { Water flow } \\
{[\mathbf{g} / \mathbf{m i n}]}\end{array}$ \\
\hline REF 1 & 283 & 5 & 61 \\
REF 2 & 276 & 5 & 94 \\
REF 3 & 296 & 7 & 80 \\
REF 4 & 285 & 6 & 65 \\
REF 5 & 295 & 5 & 82 \\
REF 6 & 290 & 5 & 100 \\
\hline CAPS 1 & 296 & 11 & 54 \\
CAPS 2 & 290 & 3 & 15 \\
CAPS 3 & 276 & 13 & 47 \\
CAPS 4 & 276 & 6 & 37 \\
CAPS 5 & 286 & 3 & 0 \\
CAPS 6 & 296 & 6 & 13 \\
\hline
\end{tabular}

\subsection{Comparison between the Spacer technique and the CFRP technique}

Both crack control techniques require approximately the same time. For the Spacer technique a large part of the time is consumed by the cracking process, which has to happen slow $(0.5 \mu \mathrm{m} / \mathrm{s})$ in order not to have a sudden failure. For the CFRP technique the cracking process is quite fast. The time-consuming part for this technique is the iterative process of restraining the crack width and subsequently determining the crack width. However, it should be mentioned that a trained operator can significantly reduce the required time of the process. In theory, it is even possible to obtain the desired crack width almost perfectly, but this would require an impractical amount of time.

When comparing the results of the two techniques it is clear that the crack widths of the specimens controlled according to the CFRP technique are much closer to the intended crack width than the crack widths of the specimens controlled with the Spacer technique (an average crack width of $287 \mu \mathrm{m}$ obtained with the CFRP technique compared to an average crack width of 323 $\mu \mathrm{m}$ obtained with the Spacer technique). Furthermore, it is clear that the variance on the crack width is significantly lower for the CFRP technique than for the Spacer technique (a COV of $2.8 \%$ compared to a $\mathrm{COV}$ of $11.8 \%$ ).

The higher accuracy of the crack widths of the specimens controlled with the CFRP technique translates into a lower variability of the water flow results with 
respect to the results obtained with the Spacer technique. This can be seen by comparing the variability of the water flow values of the REF specimens of the two techniques. For the specimens controlled according to the Spacer technique the COV is equal to $26.4 \%$, while for the specimens controlled according to the CFRP technique the COV is equal to $19.1 \%$.

It is important to note that the COV on the water flow results can be an order of magnitude higher than for the crack width results. Thus, reducing the variability of the crack width is important but the variability on the water flow will remain significant even if crack control techniques are applied. This higher variance on the water flow results is, among others, caused by the internal geometry of the crack which cannot be measured by optical microscopy.

Despite the lower mean crack width for the CFRP technique, the obtained sealing efficiency is lower than the one obtained with the Spacer technique. For the Spacer technique the cracking process is slower which results in more capillary action helping to release the healing agent from the capsule.

\section{Conclusion}

Comparison of a crack control technique using spacers (Spacer technique) with a crack control technique using an iterative approach of restraining and measuring of the crack width (CFRP technique) shows that:

- The use of the CFRP technique results in a low variability on the crack width.

- For the Spacer technique the used spacers were most likely too deformable, resulting in a higher variance on the crack width compared to the one obtained with the CFRP technique.

- The variance on the water flow results is lower for the CFRP specimens than for the Spacer specimens. This is the result of the lower variability on the crack width for the CFRP specimens.

- The water flow results have a variance which is of a magnitude higher than the variance on the crack widths. One of the reasons for this is the unknown internal geometry.

- For both techniques the used self-healing strategy resulted in a good sealing efficiency. The sealing efficiency obtained with the spacer technique is higher than the one obtained with the CFRP technique as a result of a higher capillary action.

This research was supported by a grant (18SCIP-B103706-04) from the Construction Technology Research Program funded by the Ministry of Land, Infrastructure and Transport of the Korean government. TRADECC and ENCI are thanked for their generous donation of CFRP, respectively cement.

\section{References}

1. C. Edvardsen. Water permeability and autogenous healing of cracks in concrete. Materials Journal. (1999);96(4):448-54.
2. E. Gruyaert, B. Debbaut, D. Snoeck, P. Díaz, A. Arizo, E. Tziviloglou, et al. Self-healing mortar with $\mathrm{pH}$-sensitive superabsorbent polymers: testing of the sealing efficiency by water flow tests. Smart Materials and Structures. (2016);25(8):084007.

3. E. Tziviloglou, V. Wiktor, J. Wang, K. Paine, M. Alazhari, A. Richardson, et al., editors. Evaluation of experimental methodology to assess the sealing efficiency of bacteria-based self-healing mortar: round robin test. RILEM Conference on Microorganisms-Cementitious Materials Interactions; 2016: RILEM.

4. V. Achal, A. Mukerjee, M. S. Reddy. Biogenic treatment improves the durability and remediates the cracks of concrete structures. Construction and Building Materials. (2013);48:1-5.

5. B. Van Belleghem, R. Montoya, J. Dewanckele, N. Van den Steen, I. De Graeve, J. Deconinck, et al. Capillary water absorption in cracked and uncracked mortar-A comparison between experimental study and finite element analysis. Construction and Building Materials. (2016);110:154-62.

6. D. Palin, H. M. Jonkers, V. Wiktor. Autogenous healing of sea-water exposed mortar: Quantification through a simple and rapid permeability test. Cement and Concrete Research. (2016);84:1-7.

7. E. Tziviloglou, H. M. Jonkers, E. Schlangen. Bacteria-based Self-Healing Concrete to Increase Liquid Tightness of Cracks. First conference on ageing of materials and structures; Delft, The Netherlands (2014). p. 650-5.

8. E. Tziviloglou, V. Wiktor, H. Jonkers, E. Schlangen. Bacteria-based self-healing concrete to increase liquid tightness of cracks. Construction and Building Materials. (2016);122:118-25.

9. J. Feiteira, E. Gruyaert, N. De Belie. Self-healing of moving cracks in concrete by means of encapsulated polymer precursors. Construction and Building Materials. (2016);102:671-8.

10. K. Van Tittelboom, N. De Belie, D. Van Loo, P. Jacobs. Self-healing efficiency of cementitious materials containing tubular capsules filled with healing agent. Cement and Concrete Composites. (2011);33(4):497-505.

11. B. Van Belleghem, K. Van Tittelboom, N. De Belie. Efficiency of self-healing cementitious materials to reduce water ingress through cracks. Materiales de Construcción. (to be published).

12. P. Van den Heede, B. Van Belleghem, N. Alderete, K. Van Tittelboom, N. De Belie. Neutron radiography based visualization and profiling of water uptake in (un) cracked and autonomously healed cementitious materials. Materials. (2016);9(5):311.

13. M. Maes, K. Van Tittelboom, N. De Belie. The efficiency of self-healing cementitious materials by means of encapsulated polyurethane in chloride containing environments. Construction and Building Materials. (2014);71:528-37. 